\title{
A pós-graduação em educação no Norte e Nordeste: desafios, avanços e perspectivas
}

\author{
Betania Leite Ramalho \\ Universidade Federal do Rio Grande do Norte, \\ Programa de Pós-Graduação em Educação
}

\section{Vicente de Paulo Carvalho Madeira}

Fundação Educacional Serra dos Órgãos,

Diretoria de Pós-Graduação, Pesquisa e Extensão

\section{Introdução}

A pós-graduação em educação nas regiões Norte e Nordeste parece hoje irreversivelmente consolidada. Do Amazonas à Bahia encontram-se cursos e programas ${ }^{1}$ que têm crescido em quantidade e se desenvolvido em qualidade, como demonstrado nas avaliações oficiais, na crítica e na aceitação da comunidade. É uma marca visível no atual estágio dos programas das duas regiões uma nova cultura acadêmico-científica. Não se trata apenas de indicadores mensuráveis estatisticamente, mas de novo patamar

\footnotetext{
${ }^{1}$ As designações “curso de mestrado" e "curso de doutorado" foram utilizadas durante muitos anos pela Coordenação de Aperfeiçoamento de Pessoal de Nível Superior (CAPES). Mais recentemente, passou-se a nomear programa de pós-graduação a existência integrada do mestrado e do doutorado em uma mesma instituição. Conceitualmente, significou também a pós-graduação ancorada na pesquisa, e não apenas no ensino, como ocorreu nos primeiros anos de sua implantação. Neste artigo, mantivemos a dupla nomenclatura de cursos e programas, por ainda existirem, nas regiões Norte e Nordeste, mestrados sem doutorados.
}

nas relações constitutivas de cursos e programas, na formação e na pesquisa. Essa situação, porém, é o resultado de uma longa caminhada que envolveu vários fatores e muitos atores, em diversas etapas, no tempo psicossocial e nos espaços geopolíticos.

Nesse quadro, ressalta-se a participação das universidades públicas federais e, mais recentemente, também de universidades estaduais. O que se destaca são novos e promissores grupos de docentes pesquisadores e de pós-graduandos envolvidos com seriedade e dedicação numa proposta de produção do conhecimento, de sua difusão e aplicação.

A recuperação dessa memória seria objeto de aprofundamento em uma pesquisa maior. Nos limites deste artigo, propomo-nos a um esforço de recuperação de alguns aspectos de uma construção coletiva, numa perspectiva crítica, como referência para posterior aprofundamento. Não temos a pretensão de uma análise histórico-documental sobre essa evolução; objetivamos tão-somente uma reflexão engajada numa prática desenvolvida durante duas décadas e meia, inserindo-nos como parte dessa construção.

Nessa delimitação de objeto, não poderemos descer à profundidade da consideração particular das ex- 
periências desenvolvidas em cada estado das duas regiões, mas elas permanecem como referência para nosso objetivo de tecer um conjunto de considerações de caráter geral.

\section{O contexto global da pós-graduação no país}

O processo institucional da pós-graduação no Brasil está completando, neste ano de 2005, seus 40 anos, considerando-se como marco referencial o parecer $n^{\circ}$ 977, aprovado em 3 de dezembro de 1965 pela Câmara de Ensino Superior do então Conselho Federal de Educação. Mais conhecido pelo nome do seu relator, Newton Sucupira, esse documento cumpriu o objetivo de definir e regulamentar a natureza e os objetivos da pós-graduação no país.

Em 1966 foi criado o mestrado em educação da Pontifícia Universidade Católica do Rio de Janeiro (PUC-Rio), e a partir de então iniciou-se um longo processo de instalação e regulamentação de cursos e programas, até o estágio atual. O desenvolvimento da pós-graduação em educação, como nas demais áreas, vai acontecer no contexto do projeto de modernização conservadora, capitaneado, nas suas origens, pelo regime militar, cujas metas, definidas nos planos de desenvolvimento nacional implantados no pós-1964, apontam para a formação de recursos humanos qualificados para todos os níveis de ensino, a preparação de pesquisadores de alto nível e a capacitação avançada de profissionais.

Nesse contexto, a pós-graduação em educação desenvolveu-se de maneira lenta e progressiva como o mais alto nível do ensino na área. Nesse percurso atinge a maturidade quarentona de uma longa travessia por vales e montes, desertos e oásis. A história de cada curso ou programa é uma verdadeira saga, com seu tributo às contradições internas do sistema. Terse-á, porém, atingido a terra prometida?

Há um certo otimismo em relação à pós-graduação brasileira, como se ela fosse imune aos vícios atávicos do sistema educacional na sua relação com a estrutura social. Afinal de contas, a qualidade que the foi atribuída não poderia deixar de estar relacionada com sua real destinação. A questão fundamental, do ponto de vista sociopolítico, é: a quem e para que se destina a pós-graduação no sistema social brasileiro? A própria distribuição dos programas ainda hoje obedece aos determinismos das assimetrias e disparidades regionais e estaduais. Por certo corporativismo, é a própria comunidade acadêmica que enaltece as características da pós-graduação, omitindo seus problemas de concepção, estrutura e funcionamento. Muitas vezes nem se percebe a reprodução, feita na pós-graduação, das insuficiências e deficiências da graduação. Nem se explora a profunda vinculação da pós-graduação com a estratificação social elitista, como se o chamado projeto da universidade brasileira se constituísse e se construísse à margem das contradições e dos conflitos que ocorrem na dinâmica social. Qual o empenho que se vê da pós-graduação na luta pela universalização e pela qualidade do ensino fundamental, médio e superior, como mecanismo político de fortalecimento das bases populares?

A Associação Nacional de Pós-Graduação e Pesquisa em Educação (ANPEd) vem reafirmando sua posição, ao longo dos anos, a esse respeito. Em vários documentos, expressa que "a pós-graduação não se coloca absolutamente à parte no sistema educacional. Pela nova [Lei de Diretrizes e Bases da Educação Nacional] LDB, integra-se na educação superior e articula-se com os demais níveis, sendo seu papel delineado nas inter-relações e exigências propostas pela atual legislação da educação brasileira, mas, acima de tudo, pelo movimento histórico-social em que se insere" (Gatti, 1999, p. 35).

Já no fim da década de 1970 o então ministro da Educação, Eduardo Portela, assumia o cargo denunciando, segundo divulgação da imprensa à época, o que chamou de "orgia da pós-graduação". Com efeito, importava considerar que a prioridade da base educacional se havia deslocado para o reforço das elites, no topo da pirâmide, assegurando o privilégio de um ensino superior de alta qualidade, elevando o patamar de excelência antes localizado no ensino de graduação.

O avanço da pós-graduação corresponde à abertura dos portões da universidade para o acolhimento 
da demanda, cedendo à pressão social, com a concomitante desvalorização dos diplomas e títulos da graduação, bem como da pós-graduação lato sensu, sem dúvida mais democratizada que a pós-graduação stricto sensu.

Além dessa breve análise de cunho sociopolítico, a autocrítica da pós-graduação em educação teria de ser feita também do ponto de vista da concepção do conhecimento, de sua construção, de sua disseminação e aplicação. Há, portanto, desafios a serem superados, típicos de uma área que procura avançar para a consolidação de seu perfil epistemológico. A falta de preparação e experiência acadêmica e metodológica específica dos próprios docentes transferiu para a pós-graduação deficiências e insuficiências estruturais da graduação, reproduzindo-se, em um nível mais alto, o conteudismo de disciplinas atomizadas, sem uma visão de totalidade na formação e na pesquisa e, sobretudo, sem uma atenção maior à realidade histórica a ser recriada.

Marcados pela educação bancária e cartorial que recebemos, muitos professores da pós-graduação se constituíram em patrões e capatazes de um poder acadêmico que reproduz o poder exercido numa sociedade de classes. Muitas vezes os pós-graduandos são apenas alunos, no sentido etimológico do termo, e os professores são os detentores do poder e do saber, no domínio do capital intelectual. Em vez de relações dialógicas numa comunidade de trabalho acadêmico, continuam sendo mantidas relações de dominação.

Mesmo assim, podemos afirmar que a pós-graduação no país, e na área da educação particularmente, é, sem dúvida, uma experiência consolidada, tendo atingido significativo êxito, com bons resultados a contabilizar, seja na preparação de recursos humanos de alto nível, seja na produção científica, seja na criação da identidade das diferentes áreas. Permanece ainda em questão, na institucionalização da universidade brasileira, uma nova cultura acadêmica e científica apoiada na construção do conhecimento e não na sua simples transmissão, pelo desenvolvimento interpessoal e disseminação do novo por meio da pesquisa.
Aqui está o grande desafio da pós-graduação brasileira.

Este diagnóstico crítico foi a base da reação, uma das bandeiras de luta e da mobilização regional do Nordeste e do Norte em torno de uma proposta renovadora de pós-graduação em educação, o que se fez enfrentando muitas dificuldades, inclusive a descrença na capacidade dos grupos emergentes de produzir algo de novo e consistente.

\section{Um repassar histórico}

Escolhemos a linha de evolução oferecida pelos sucessivos planos nacionais de pós-graduação para repensar o processo evolutivo da pós-graduação em geral, no país e no Norte e Nordeste. Partimos do pressuposto de que esses planos nacionais permitem compreender a gênese desse sistema, seu desenvolvimento e avanço, mostrando para onde caminhou a pós-graduação em educação em cada fase dessa história.

Nos anos de 1970, no regime autoritário militar, a pós-graduação cresceu no país por uma pressão natural da expansão do ensino superior, resultante do próprio pacto político de sustentação do governo. Tratava-se de qualificar os quadros docentes, relativamente improvisados, para responder ao desafio da grande expansão do ensino de graduação, especialmente no sistema federal, e de modo particular no Norte e no Nordeste. A pós-graduação destacava-se como o mecanismo de formação dos "mestres" que garantiria a qualidade acadêmica e didática do ensino do então chamado terceiro grau. Foi o tempo dos mestrados. Fez-se o primeiro plano nacional para uma articulação coerente do desenvolvimento da pós-graduação.

O $1^{\circ}$ Plano Nacional de Pós-Graduação (1 ${ }^{\circ}$ PNPG), para o período 1975-1980, foi implantado com abundantes recursos governamentais em relação à demanda relativamente reduzida. Dir-se-ia que nem foi possível aproveitar como se deveria as verbas disponíveis, pela falta de capacidade instalada. Naturalmente, por fatores estruturais e mesmo geopolíticos, a região Sudeste absorveu a maior par- 
cela dessas verbas, fato que repercute ainda hoje na sua posição consolidada. Mas não se pode negar a atenção dispensada às regiões periféricas para a criação dos primeiros cursos de mestrado. No ano de 1980, o Nordeste contava com cinco cursos de mestrado em educação, todos enfrentando as dificuldades de sua própria marginalidade em um sistema com alto nível de centralização e concentração no Sudeste.

Desde essa época instalou-se e foi-se desenvolvendo um sistema nacional de avaliação, sempre polêmico, mas que gradativamente se impôs pelo pacto do aparelho estatal com a própria comunidade acadêmica, na chamada "avaliação entre pares". Desse modo, no que diz respeito à concretização das metas do $1^{\circ}$ PNPG, podem ser apontados como resultados fundamentais a implementação de medidas de expansão dos cursos de mestrado e doutorado, particularmente medidas voltadas para a qualificação dos docentes do ensino superior, e o estabelecimento do sistema de avaliação.

O $2^{\circ}$ PNPG, para o período 1982-1985, surgiu no contexto de forte crise política que sinalizava o ocaso dos governos militares. Estes enfrentaram o enfraquecimento de suas bases de legitimidade pelo esgotamento do modelo econômico implantado, em decorrência das condições internacionais adversas à continuidade de um crescimento altamente dependente de capitais externos, fonte das dívidas externa e interna que ainda hoje dominam o cenário nacional. Não se pode negar, no entanto, que o $2^{\circ}$ PNPG tenha dado ênfase à qualidade do ensino superior e da pós-graduação, e buscado adequar o sistema pós-graduado às necessidades do país em termos de produção de ciência e tecnologia, tornando bastante evidente sua vinculação com o setor produtivo. As prioridades estabelecidas deram passo à racionalização dos investimentos, ao reforço dos mecanismos de acompanhamento e avaliação, com vista à melhoria da qualidade dos mestrados e doutorados. Em sua vigência, foram feitos esforços no sentido de dotar as regiões Norte e Nordeste de uma rede de cursos que reduzisse a dependência regional, no contexto da pós-graduação nacional.
O $3^{\circ}$ PNPG, para o período 1986-1989, coincide com o primeiro governo civil da Nova República e com a retomada do processo de redemocratização política. Fruto do contexto de crise econômica, o $3^{\circ}$ PNPG novamente procurou estreitar o relacionamento entre a universidade, a pós-graduação e o setor produtivo, dando maior força à necessidade de institucionalização da pesquisa como elemento indissociável do ensino de pós-graduação, e sua integração no Sistema Nacional de Tecnologia. A universidade pública foi considerada locus privilegiado para a produção de conhecimento, enfatizando-se seu papel no desenvolvimento nacional.

Nas regiões Norte e Nordeste, na área de educação, o desafio era a fixação de pessoal de nível superior com a qualificação e produtividade exigidas para o padrão de excelência acadêmica. Algumas instituições procuraram contratar profissionais experientes, vindos até do exterior, tendo conseguido resultados consideráveis, apesar do turnover estabelecido. Algumas iniciativas de criação de doutorado foram estudadas, procurando-se associar várias instituições em uma proposta de programa integrado. Na segunda metade dos anos de 1980, o sonho dos mestrados em educação do Nordeste era articular-se para a formação de um consórcio que pudesse oferecer um forte doutorado. Essa proposta pouco a pouco revelou-se inviável. Foi criado, inicialmente, o doutorado em educação da Faculdade de Educação da Universidade Federal da Bahia (UFBA), em 1992, seguido pelos similares da Universidade Federal do Ceará (UFC) e da Universidade Federal do Rio Grande do Norte (UFRN), em 1994, da Universidade Federal de Pernambuco (UFPE), em 2002, e por último o da Universidade Federal da Paraíba (UFPA), em 2003. Registre-se também a tentativa da criação do doutorado na Faculdade de Educação da Universidade Federal do Amazonas (UFAM), depois suspenso e com seus doutorandos absorvidos por outros programas da região Nordeste.

Após o $3^{\circ}$ PNPG houve um período em que nenhum outro plano vingou no âmbito do governo federal para a pós-graduação nacional, o que se explica 
pelas circunstâncias da evolução do Estado brasileiro. Isso não significou, porém, a ausência de políticas por parte dos últimos governos, conduzidas prioritariamente pela CAPES. Embora não houvesse formalmente, nos anos de 1990, um $4^{\circ}$ PNPG, houve um conjunto de medidas que constituem uma política para a pós-graduação.

A promulgação das novas Diretrizes e Bases da Educação Nacional (lei no 9.394/96) trouxe novas exigências para a pós-graduação, enquanto determina que a preparação para o exercício do magistério superior se faça prioritariamente em programas de mestrado e doutorado (art. 66) e preceitua que a expansão diferenciada da pós-graduação seja balizada por critérios de qualidade acadêmica.

Analisando esse conjunto de medidas, poderemos destacar as seguintes, implementadas com a intenção de promover a expansão do sistema de pósgraduação do país:

a) intensificação da capacitação docente das instituições de ensino superior, priorizando os estabelecimentos universitários para atender à expansão do ensino de graduação e à elevação de sua qualificação acadêmica;

b) formação de profissionais de alto nível para atender às demandas dos diversos mercados de trabalho nos setores públicos e privados;

c) redução do tempo de titulação médio na pósgraduação, julgando-se que os tempos são elevados em razão do próprio modelo seqüencial em que se tem o mestrado como etapa prévia e obrigatória para o doutorado, faltando uma visão ampla de programa de pós-graduação;

d) reorganização da estrutura de financiamento da pós-graduação;

e) aprimoramento constante da qualidade dos programas, utilizando um modelo de avaliação pautado em indicadores internacionais;

f) proposição de ações para reduzir o desequilíbrio regional por intermédio de estratégias que promovam a fixação de competências acadêmicas e de pesquisa.
Paradoxalmente, é forçoso reconhecer que esse período em que não se teve um plano nacional de pósgraduação está marcado por um grande salto de qualidade e de quantidade na pós-graduação no Norte e Nordeste. Registra-se, especialmente, o resultado do investimento social feito na formação de pessoal, contando-se agora com grupos de docentes-pesquisadores com doutorado e pós-doutorado, formados em outros centros do país e do exterior, com melhores condições de fixação local por sua vinculação de origem. Chegou-se ao estágio atual de desenvolvimento, no qual se vislumbram desdobramentos muito positivos para o período 2005-2010, abrangido pelo $5^{\circ} \mathrm{PNPG}$.

Aprovado em 5 de janeiro de 2005, o $5^{\circ}$ PNPG incorpora o princípio de que o sistema educacional é fator estratégico no processo do desenvolvimento científico, cultural, tecnológico e social do país. Nele, a educação é uma referência institucional indispensável à formação de recursos humanos altamente qualificados e ao potencial científico-tecnológico nacional.

Esse $5^{\circ}$ Plano propõe, no período de seis anos, dotar o Brasil de mais 16.000 doutores e 45.000 mestres, e prevê um acréscimo no orçamento de bolsas e fomento no valor de R\$1,66 bilhões. Projeta que, alcançadas essas metas, o Brasil atingirá, em 2010, o número de doutores por 100 mil habitantes equivalente ao nível alcançado pela Coréia em 1985.

Olhando para a área da educação, e especificamente para as regiões Norte e Nordeste, os desafios são grandiosos. Ao contrário, porém, de outras épocas, hoje essas regiões dispõem de capacidade instalada em condições de responder a essa demanda, apesar dos históricos desequilíbrios regionais e intraregionais do país, que se reproduzem na mentalidade e na visão da própria academia. De toda forma, percebe-se um amadurecimento no discurso das representações regionais. Antes, o enfoque estava muito mais nas discrepâncias regionais; hoje, volta-se de preferência para as políticas públicas da educação.

Atualmente, o Sistema Nacional de Pós-Graduação apresenta expressivo avanço, apesar da forte diversidade marcada por aqueles desequilíbrios entre as regiões e estados. Isso, porém, não é causa em si 
mesmo, mas efeito de causas estruturais que não se modificam pelo simples discurso de reclamação ou reivindicação. O país, como um todo, já exibe indicadores de excelência. Basta tomar dois indicadores: a taxa de crescimento $(16,1 \%)$ do número de doutores é bem expressiva se comparada com a de outros países; é crescente a participação relativa de autores nacionais nas publicações em periódicos internacionais indexados (1,44\% em 2001). No entanto, muito embora o sistema de pós-graduação tenha atingido bons resultados, ainda falta muito para chegar a cumprir seu objetivo principal: “o crescimento equânime, com o propósito de atender, com qualidade, as diversas demandas da sociedade, visando o desenvolvimento científico, tecnológico, econômico e social do país” (Brasil, 2004, p. 54)

A oferta da pós-graduação em educação nas cinco regiões, nos níveis de mestrado e doutorado (73 programas no total, em 2005), apresenta-se com os seguintes percentuais: Sudeste: $45 \%$ mestrado e $56 \%$ doutorado; Sul: 26\% mestrado e 17\% doutorado; Nordeste: $16 \%$ mestrado e $17 \%$ doutorado; CentroOeste: $9 \%$ mestrado e $10 \%$ doutorado; Norte: 4\% mestrado e nenhum doutorado. Se considerarmos somente os doutorados, a concentração dos programas no eixo Sul-Sudeste é ainda maior: as regiões Sul e Sudeste detêm 73\% dos programas de pós-graduação no país (Brasil, 2005).

O notório desequilíbrio da pós-graduação entre as regiões é apenas um aspecto do desequilíbrio total de um país desigual e injusto, por força do modelo de desenvolvimento econômico e social historicamente implantado. Várias declarações sobre a política de pósgraduação defendem que, se não for efetivada uma eficiente ação governamental para fazer frente a tais desequilíbrios, esse fosso acadêmico deve aprofundarse cada vez mais. Acontece que esse problema é uma decorrência de outros fatores, e continuará a existir necessariamente enquanto suas causas estruturais não forem superadas pela estreita vinculação entre o crescimento econômico e a fixação de competências, que, no final deste século, se delineia como fundamental para o desenvolvimento das regiões.

\section{A questão da avaliação}

Para quem viveu a problemática da pós-graduação em educação no Norte e Nordeste nos anos de 1990, ainda está muito viva a lembrança dos traumas do processo de avaliação. Os programas estavam submetidos a um drama periódico pouco esclarecido e pouco consciente, marcado por sérias contradições. Entendemos ser essa a questão central na problemática de nossos cursos e programas nesta década, e retomamos aqui um texto apresentado e distribuído no $14^{\circ}$ Encontro de Pesquisa em Educação do Nordeste (EPEN) (Salvador-BA, 1999), a partir de então tornado do Norte e Nordeste (EPENN), como indicador da integração das duas regiões (Madeira, 1999).

No ano de 1998, assistiu-se nacionalmente a uma grande reação aos resultados da avaliação praticada pela CAPES. Anteriormente, na avaliação realizada em 1996, referente ao biênio 1994-1995, um único documento havia sido produzido e nacionalmente divulgado sobre aquela avaliação bienal: Decifra-me ou devoro-te: o enigma de uma avaliação da $\mathrm{CAPES}^{2}$ (Madeira, 1996), um manifesto público do Programa de Pós-Graduação em Educação da UFRN, distribuído na reunião do Fórum de Coordenadores dos Programas de Pós-Graduação em Educação, realizada em Brasília no mês de maio de 1997. Em 1998, porém, a crítica e a indignação percorreram todo o país. A insatisfação foi contida, de certo modo, no âmbito do Fórum de Coordenadores dos Programas, mas irrompeu aberta e claramente na Assembléia Geral da $21^{\text {a }}$ Reunião Anual da ANPEd, realizada em setembro de 1998, em Caxambu.

${ }^{2}$ Análise da avaliação e da conceituação feitas pela Comissão de Avaliação da área de educação, pelo Comitê Científico da CAPES, sobre os cursos de doutorado e de mestrado do Programa de Pós-Graduação em Educação da UFRN, em novembro de 1996. Grupo de trabalho formado pelos docentes: Betania Leite Ramalho, Margot Campos Madeira, Maria Salonilde Ferreira, Marly Amarilha de Oliveira e Vicente de Paulo Carvalho Madeira, redator do texto. 
Esse acontecimento não foi imprevisto, surgiu de reflexões sobre o problema, em vários cursos e programas, ${ }^{3}$ assim como nas instâncias dos fóruns regionais e nacional. A conferência da professora Bernardete Gatti, na referida reunião da ANPEd, trouxe ao debate subsídios e fundamentos para que a crítica já desenvolvida pudesse chegar a sua manifestação plena, representativa da área, provocando a “descredibilização” de todo o processo avaliativo, por suas falhas e equívocos, insuficiências e deficiências, tanto conjunturais quanto estruturais.

Com base nessa discussão, o que valeriam, ainda, para a comunidade acadêmica, as questionáveis "notas" da escala de um a sete atribuídas aos diferentes cursos e programas? A "relativização" desses resultados afastou o fantasma classificatório, restabelecendo a autoconfiança necessária a um processo de construção coletiva. Da superação dessa crise surgiu a esperança de um diálogo real entre "pares" na avaliação dos cursos e programas, e de uma nova postura na relação com a nova comissão de avaliação constituída pelos "pares”.

A partir dezembro de 1998 passou a circular pelos cursos e programas um texto produzido por uma comissão criada pela Diretoria da ANPEd, em decorrência de decisão tomada pela Assembléia Geral realizada na $21^{\text {a }}$ Reunião Anual (Gatti et al., 1999). Esse documento retomou os questionamentos levantados nessa reunião, sistematizando-os e fundamentandoos. Mas, se de um lado devia-se interpelar o sistema vigente de avaliação, de outro lado não se podia deixar de desafiar nossos "pares" sobre sua posição e sua prática. Tratava-se de superar a dependência pela

3 Na área de educação, houve documentos elaborados por diversos programas (por exemplo Universidade Federal Fluminense - UFF, Universidade de São Paulo - USP, Pontifícia Universidade Católica - PUC-SP) e pelos vários fóruns regionais. O Fórum dos Coordenadores de Programas distribuiu um dossiê completo desses documentos durante a reunião nacional da ANPEd, realizada em setembro de 1998. O assunto repercutiu também na grande imprensa, não pela área de educação. qual tudo girava em torno da avaliação externa produzida pelo sistema avaliativo da CAPES. Parecia que faltava capacidade aos programas para assumir sua autonomia.

O documento produzido pelo Programa de PósGraduação em Educação da UFRN em 1996 partiu da provocação: Quem tem medo de avaliação? Parecia que, antes de mais nada, importava enfrentar a avaliação sem complexo e sem medo. Se nos avaliássemos corretamente e se fôssemos avaliados por nossos "pares”, o que teríamos a temer? O diagnóstico de nossas possíveis insuficiências e deficiências só nos poderia ajudar. A contribuição da avaliação externa poderia ser decisiva, até mesmo para que nossas universidades assumissem suas responsabilidades. Sermos avaliados era, antes de tudo, um direito nosso, para que se manifestassem nossos pontos positivos e pudessem ser corrigidas nossas falhas. Havia uma nova postura diante do desafio. Não se tratava de pedir consideração pelas circunstâncias desfavoráveis em que se desenvolvia a pós-graduação em educação no Norte e Nordeste. Queríamos ser avaliados com os mesmos critérios unívocos e universais, com o mesmo rigor dos parâmetros, com a mesma aplicação técnica de perfis e de padrões. O medo e o complexo de inferioridade seriam produto de insegurança sobre o que estaríamos fazendo. Eles podem até ter exacerbado a agressividade de certos confrontos. Entendia-se assim que a avaliação não deveria ser uma batalha bienal (agora trienal) entre cursos e programas e avaliadores. Insistiu-se igualmente em não se colocar a reação a uma avaliação em termos de ressentimentos emocionais. A avaliação é um processo metodológico, e deve ser tratado no nível dessa racionalidade, com serenidade e competência.

Por sua vez, um dos resultados importantes da crise de 1998 foi demonstrar que a questão dos cursos classificados como fracos ou atingidos de alguma maneira pelos vieses da avaliação não era característica de determinada região. Em avaliações mais recentes isso ficou demonstrado, e o problema, antes territorializado, passou a ser posto em outros termos. Em decorrência, a renovação dos programas e cursos 
das regiões Norte e Nordeste orientou-se pelo princípio da segurança sobre o que se está fazendo na gestão acadêmica da proposta e na gerência do projeto, para que fossem superados medos e complexos.

A tese levantada no $14^{\circ}$ EPENN dizia respeito à capacidade de participar positivamente, com competência e serenidade, no processo nacional de avaliação. Era a proposta de contribuir e colaborar para que se tivesse um verdadeiro sistema de avaliação. E aqui se destacava a questão fundamental de saber se, com o nome de avaliação, não está sendo colocado um modelo de aferição estatística de dados, não se configurando a amplitude conceitual do termo. Aárea de educação é, por natureza, locus de uma competência específica sobre a questão da avaliação. Não é de se estranhar que seja ela mais sensível ao confronto com um modelo de aferição de dados tornado modelo de avaliação.

Sabíamos que essa não parecia ser a intenção nem o propósito da CAPES, que tem feito esforços no sentido de aperfeiçoamento de seu sistema, mas este mostrava-se como paradoxo dessa tentativa. Não era possível negar os méritos do Datacapes como um programa de coleta a ser devidamente utilizado numa avaliação competente, capaz de perceber e de compensar os limites desse instrumento. Mas é preciso que também os cursos e programas dominem o instrumento para não serem vítimas dele - tal como contribuintes nas "garras do leão", por imposto de renda mal declarado -, como aconteceu na avaliação dos biênios 1996-1997 e 1998-1999.

Constatava-se que, infelizmente, a pressão que os cursos e programas sofriam do sistema de avaliação terminava por condicioná-los e constrangê-los a uma atividade avaliativa limitada pelo modelo oficial, e não estruturada a partir de sua própria realidade e dinâmica. A vocação e identidade deles, sua diversidade nas várias regiões e até mesmo dentro de uma mesma região, a história e a evolução de cada um e seu contexto institucional não poderiam escapar a uma avaliação que mereça esse nome. Do contrário estaremos contradizendo na prática o que nós mesmos ensinamos sobre esse tema.
Percebia-se que, lamentavelmente, por vezes, o resultado das avaliações - num efeito perverso - deixava grupos que faziam cursos e programas em estado de desânimo e depressão, ante a discrepância entre o esforço empreendido e a avaliação recebida. Em contrapartida, porém, acontecia que certas avaliações foram o ponto de partida para uma salutar reação interna de recuperação ou de revitalização.

De qualquer modo, a posição proclamada no $14^{\circ}$ EPNN foi a de tomar a avaliação como intrínseca ao processo de desenvolvimento acadêmico, na essência da autonomia universitária e não na submissão de qualquer pressão do aparelho estatal. Esse era o desafio que parecia dever ser respondido pelos cursos e programas de pós-graduação em educação nas regiões Norte e Nordeste: sermos capazes de integrar um processo permanente e contínuo de avaliação, como dimensão essencial de nossa prática, de nosso cotidiano. Em outros termos, tratava-se de assegurar e de garantir o exercício da capacidade e da competência de cada curso ou programa ser também sujeito de sua própria avaliação, evitando a alienação ou transferência de uma prerrogativa própria.

Isso queria dizer que a avaliação não deve ser, antes de tudo, uma exigência exógena de um órgão estatal de controle burocrático. Esse aspecto não é desprezível, e até poderá ser devidamente valorizado sem ser superestimado, pois seguramente o processo de avaliação da CAPES foi, nas mediações históricas concretas, instrumento importante para a garantia de qualidade da pós-graduação.

Teoricamente, deveríamos nos avaliar, ainda que a CAPES viesse a ser extinta. A natureza do processo educacional e a especificidade do processo acadêmico de formação pós-graduada exige e requer a integração de uma avaliação teoricamente concebida, metodologicamente orientada e tecnicamente aplicada. Seria um efeito perverso do atual sistema de avaliação - e o desafio é livrar-se disso - se os cursos e programas renunciassem a sua autonomia acadêmica para adequar-se simplesmente a um esquema externo de avaliação, sem a auto-avaliação constante do seu desempenho e sem a avaliação institucional. 
Será que nós nos avaliamos? Será que dependemos, na questão da avaliação, total ou parcialmente da chamada "avaliação da CAPES" ou de qualquer outro tipo de avaliação? Se isso acontecer, seremos condenados a sempre reagir defensivamente diante da surpresa e provocação em que normalmente se constitui o resultado de necessárias e indispensáveis avaliações externas. A avaliação torna-se tribunal. A cada vez, arma-se um processo de defesa, com recursos, promotores, advogados e interpretações em várias versões e depoimentos.

Importa também não se deixar fazer da avaliação um exercício de poder e promoção de pessoas e grupos. Há um desafio que se põe à nossa cidadania. Tratase da vigilância democrática e acadêmica que impeça a transformação do mecanismo de avaliação em um instrumento de poder que se exerce sobre os cursos e programas. O sistema de avaliação deverá estar em função do desenvolvimento da pós-graduação e da pesquisa. Os órgãos oficiais e os "pares" que nele se envolvem estão "a serviço" de finalidades e objetivos maiores, e não no simples exercício de um poder de julgar o mais e o menos. O que se deve pretender? O que se objetiva com a avaliação? A avaliação é concebida como um procedimento de apoio, de fomento ao crescimento, e não como um freio nas mãos de um comando. Menos mal que, na estrutura de representação por áreas que a CAPES adota, torna-se possível o estabelecimento de uma interação permanente entre avaliadores e avaliados, numa ação tecnicamente competente sobre o objeto e politicamente capaz sobre suas circunstâncias ou sua contextualização.

Naquele contexto histórico, impunha-se superar o fantasma da avaliação classificatório-punitiva. Havia um risco real de tomar-se a avaliação como resultando apenas em um ranking que vai atestar para um “mercado" as qualidades do produto avaliado. Aí o efeito punitivo é imediato, dentro dos órgãos oficiais e, o que é pior, nas próprias instituições, pela imagem do curso ou do programa, tanto na comunidade acadêmica quanto na sociedade.

Realmente, foi marcante esse efeito punitivo da avaliação para a grande maioria dos programas, con- solidados ou não. Para as regiões Norte e Nordeste, o modelo homogeneizante e desconhecido em sua filosofia, princípios e metodologia terminou por descredenciar a grande maioria dos programas que não conseguiram atender às exigências que o modelo impunha. Implantou-se a sistemática de descredenciamento dos programas com avaliação abaixo de um certo ponto de corte (conceito $\mathrm{C}$ ou nota 3 ), incluindo aí o não- reconhecimento dos títulos emitidos aos mestres e doutores egressos desses programas. As avaliações dos últimos anos da década de 1990 trouxeram fortes crises e conflitos entre as áreas e a CAPES - sem ignorar os conflitos no interior da própria área. A educação, uma das áreas mais contestadoras, mobilizou-se e enfrentou com muita energia esse momento de mudança das regras, segundo princípios e exigências externas à realidade de muitas das áreas de conhecimento, embora o discurso oficial adotasse a retórica do combate aos desequilíbrios regionais e intra-regiões. Acirrou-se, muito, a concentração da chamada excelência, com a exclusão de programas periféricos que tardaram a ingressar ou retornar ao Sistema Nacional de PósGraduação.

A comunidade acadêmica estava desafiada a posicionar-se diante da maneira discutível como órgãos oficiais do Estado vinham conduzindo o marketing educacional por meio desses mecanismos classificatórios. Infelizmente, porém, especialistas e técnicos já puderam acusar nosso corporativismo, analisando que só reagimos quando a nota é baixa para o nosso próprio curso ou programa. Havia, no entanto, um desafio que se colocava em termos mais amplos. Tratava-se de deixar bem claro o que se está querendo com a avaliação que se faz: promover ou controlar o desenvolvimento da pesquisa e da pósgraduação? Finalmente, o texto discutido no $14^{\circ}$ EPENN introduzia a questão política da avaliação e chamava a atenção para que não a reduzíssemos a uma simples ingenuidade pedagógica. Concluía-se, porém, com a satisfação de se registrar o bom momento que se conseguira na avaliação da área de educação naquele ano. 
De fato, de 1999 para cá as regiões Norte e Nordeste têm se destacado pelo melhoramento de seu perfil e de seu desempenho na pós-graduação na área de educação. Credite-se esse sucesso a vários fatores, entre eles, porém, destaquem-se a relação da Comissão de Avaliação com a comunidade e a ação decisiva do Fórum Regional de Coordenadores, que soube articular ações concretas de cooperação interna e até de capacitação de pessoal para fazer face às necessidades do processo de gestão acadêmico-avaliativa, além da presença e atuação política das regiões no contexto nacional.

Foi, sem dúvida, um exemplar momento de superação de conflitos e tensões por uma atuação pedagógica de apoio, de fomento e parcerias entre os programas das regiões e o apoio de colegas com uma histórica contribuição no desenvolvimento acadêmico-científico dos programas dessas regiões.

\section{Conclusão}

Do ponto de vista regional, tem-se a expectativa de um crescimento do Sistema Nacional de Pós-Graduação como um todo, com a inclusão de modelos alternativos e ações que atendam às necessidades particulares. Nesse sentido, propõem-se também novos modelos e políticas de cooperação internacional visando ao aprimoramento do sistema.

Parece-nos que o cenário atual é muito favorável. O que, em meados dos anos de 1980, não havia sido possível se estabelecer, por exemplo, em termos de parcerias intra-regionais, dez anos após os programas das duas regiões encontraram o caminho da cooperação e do trabalho coletivo para sua realização. Para tanto, sem dúvida, foi importante a histórica decisão do Fórum de Coordenadores, em 1996, durante a $19^{a}$ Reunião Anual da ANPEd, de unir em um único fórum regional as regiões Norte e Nordeste, antes separadas por um critério geopolítico. Assistiu-se desde então à revitalização desse Fórum, que encontrou um caminho para a conquista coletiva no campo da pós-graduação em educação. A união e a aprendizagem conjunta têm feito a diferença que se torna visível a cada encontro regional de pesquisa, uma tradição consolidada que vem desde fins da década de 1970, por iniciativa do Programa da UFBA, e que mantém regularidade e constância, como recentemente também vem ocorrendo em outras regiões.

Como já registramos, inicialmente a pós-graduação em educação esteve vinculada à sua função de preparação de quadros para o magistério superior. Era essa a ênfase ao tempo do $1^{\circ}$ PNPG. Tratava-se da urgência da capacitação e da titulação dos quadros docentes necessários ao provimento das vagas de professor do ensino de terceiro grau. Pouco a pouco, com o desenvolvimento dos mestrados em programas completos, incluindo o doutorado, a formação para a pesquisa foi-se fortalecendo. Além do mais, cresceu a consciência acadêmica da integração indissociável entre a pesquisa e o ensino, cada vez mais visto como construção coletiva a partir da relação teoria e prática. Vieram a se desenvolver as linhas de pesquisa como trilhos sobre os quais corre o processo da pós-graduação, numa nova dinâmica que vem demandando a sua própria reestruturação curricular e metodológica. Assim, gradualmente se chegou a uma nova concepção da pós-graduação, com a pesquisa assumindo papel definidor, não sem o duplo risco do descuido da formação pedagógica e didática de novas gerações de mestres e doutores, e da vulgarização ou da superficialidade da pesquisa.

Neste momento, a questão crucial para a pósgraduação em educação nas regiões Norte e Nordeste prende-se à sua relevância: como fazê-la avançar para fortalecer a pesquisa como base formativa do desenvolvimento profissional? Qual a contribuição efetiva da pós-graduação em educação para o desenvolvimento regional? Trata-se de dar um perfil próprio à pós-graduação, que se desenvolve não para satisfazer a um modelo provavelmente bem sucedido alhures, mas para dar uma resposta à problemática do desenvolvimento, inclusive educacional, da região em que se situa.

Em outros termos, cresce a consciência de que não se tem a esperar que venham de outras regiões as 
soluções educacionais de que carecem as regiões Norte e Nordeste. Qual deve ser, pois, o compromisso das instituições de ensino superior, de seus docentes pesquisadores e de seus pós-graduandos, reunidos em grupos e linhas de pesquisa, para enfrentar o quadro exposto das disparidades e as exigências do desenvolvimento econômico, social e político? Que esperar dos programas de pós-graduação em educação, dos mestres e doutores em educação dessas regiões com tantas demandas socioeducacionais?

A primeira proposta é lutar pelo avanço de uma cultura pós-graduada nas regiões em questão, incentivando, desde a graduação, a institucionalização da pesquisa no processo acadêmico do ensino-aprendizagem, na construção coletiva do conhecimento histórica, social e politicamente relevante. Para isso, fazem-se necessários recursos de várias ordens:

a) insistir no empenho relativo à iniciação científica dos graduandos, continuando o bem-sucedido programa de incentivo institucional de bolsas, em especial o Programa Institucional de Bolsas de Iniciação Científica (PIBIC);

b) ampliar, não só quantitativa, mas qualitativamente, o engajamento de novos professores pesquisadores no Sistema Nacional de Pós-Graduação e apoiar o avanço da pós-graduação nas instituições de ensino superior estaduais das duas regiões;

c) consolidar os grupos de pesquisa para a produção e a difusão do conhecimento e para fornecerem base e consistência ao desenvolvimento da pós-graduação;

d) garantir condições à produtividade acadêmica e científica dos grupos e das linhas de pesquisa, de modo que se destaque a participação regional no conjunto do país;

e) apoiar a consolidação e a emergência de lideranças, para que seja possível desenvolver a participação regional, ocupando espaços junto às instâncias de decisão, órgãos formuladores e implementadores das políticas, dada a constatação de que $\mathrm{f}$ ) as duas regiões carecem de maior representatividade em todas as esferas do sistema nacional de educação.

Essa dimensão política não aparece como algo separado da própria natureza dos programas acadêmicos. Os programas de pós-graduação em educação nas regiões Norte e Nordeste devem incorporar essas discussões no contexto dos seus projetos formativos. Faz-se necessário conhecer os rumos das políticas e participar de suas definições e aplicações. Há uma militância acadêmico-política que precisa ser ampliada nessas regiões. Nesse sentido, destaca-se sua participação ativa no âmbito das associações científicas, técnicas e acadêmicas, além daquelas sindicais e de representação de classe.

A ANPEd é um espaço importante para que os pesquisadores seniores e juniores das duas regiões nela se insiram, se incorporem aos seus grupos de trabalho e participem dos debates nacionais. Como representação da comunidade acadêmica e científica da área da educação, ela pode e deve constituir-se, cada vez mais, em instância de colaboração e pressão para mudanças.

Ao refletirmos sobre os desafios contemporâneos e as demandas recebidas pela área de educação, não podemos deixar de considerar os compromissos que lhe são inerentes: a construção da cidadania, a emancipação humana e a conquista da transformação da sociedade. Toda ação no campo educacional, inclusive a pesquisa, tem o compromisso fundamental com a formação do povo e a consolidação da cidadania, fato que se expressa no referencial das temáticas que dão sustentação às inúmeras linhas de pesquisa do conjunto dos programas. Esse clima acadêmico de engajamento tem sido manifesto nos encontros regionais que ocorrem anualmente.

Nessa perspectiva social, política e ética, a única justificativa para sustentar a existência e o avanço da pós-graduação em educação está nesse compromisso com a produção de conhecimento, com a pesquisa articulada à formação de pesquisadores comprometidos com a consolidação da cidadania. Assim que, além das escolhas de temas/problemas socialmente relevantes, 
A pós-graduação em educação no Norte e Nordeste: desafios, avanços e perspectivas

os docentes, os pós-graduandos e os próprios programas não podem perder de vista essa finalidade intrínseca e imanente do conhecimento: contribuir intencionalmente para a emancipação dos homens e para a diminuição das desigualdades entre eles.

Como construtora de inovação intelectual e atitude profissional emancipadora, a pesquisa deve provocar mudanças na forma de o pesquisador conceber e agir em seu trabalho de docente formador ou em formação nos variados campos de inserção da educação. Dessa forma, não seria este o princípio político-científico-pedagógico que deve fundamentar toda a pós-graduação em educação, embora a educação não seja o único instrumento de mudança social?

BETANIA LEITE RAMALHO, doutora em ciências da educação pela Universidade Autônoma de Barcelona, na Espanha, é professora adjunta no Departamento de Educação da Universidade Federal do Rio Grande do Norte (UFRN), e atual presidente da Associação Nacional de Pós-Graduação e Pesquisas em Educação (ANPEd) (biênio 2004-2005). Últimas publicações: em co-autoria com Isauro Beltrán Nuñez (UFRN) e Clermont Gauthier (Universidade Laval e CRIFPE/Quebec/Canadá), Formar o professor. Profissionalizar o ensino: perspectivas e desafios (Porto Alegre: Sulina, 2004, $2^{\text {a }}$ ed.); organizado com Isauro Beltrán Nuñez, Fundamentos do ensino-aprendizagem das ciências naturais e da matemática: o novo ensino médio (Porto Alegre: Sulina, 2004); em co-autoria com Isauro Beltrán Nuñez, Estudo das necessidades formativas de professores/as do ensino médio (Porto Alegre: Sulina, 2005). No Programa de Pós-Graduação em Educação da UFRN, coordena a linha de pesquisa "Formação e profissionalização docente, com os projetos: A passagem do ensino médio à universidade; o acesso e a inclusão de alunos da rede pública à universidade pública, e Representação de professores(as) em formação sobre a profissão e a profissionalização do trabalho docente (em colaboração com Isauro Beltrán Nuñez).E-mail: betania.ramalho@terra.com.br

VICENTE DE PAULO CARVALHO MADEIRA, doutor em ciências da educação pela Université René Descartes (Paris V) e com pós-doutorado no Institut International de Planification de l'Éducation (IIPE/ Organização das Nações Unidas para a Educação, a Ciência e a Cultura - UNESCO), é atualmente diretor de pós-graduação, pesquisa e extensão da Fundação Educacional Ser- ra dos Órgãos, em Teresópolis, estado do Rio de Janeiro. Nessa instituição participa da linha de pesquisa Avaliação institucional, pela qual publicou: O desafio institucional da concepção e integração das funções de pesquisa, ensino e extensão (Revista Brasileira de Política e Administração da Educação, v. 19, nº 2, jul.-dez. 2003, p. 213-220) e Reflexões sobre avaliação de teses e dissertações (Avaliação - Revista da Rede de Avaliação Institucional da Educação Superior, v. 8, nº 4, dez. 2003, p. 121-139). E-mail: vmadeira@centroin.com.br

\section{Referências bibliográficas}

ANPEd - Associação Nacional de Pós-Graduação e Pesquisa, (2005). V Plano Nacional de Pós-Graduação: subsídios apresentados pela Anped. Revista Brasileira de Educação, $\mathrm{n}^{\circ}$ 27, set.-dez., p. 198-202.

BRASIL, (2004). V Plano Nacional de Pós-Graduação (20052010). Brasília: MEC/CAPES.

(2005). Programas reconhecidos. Brasília: MEC/CAPES. Bases de dados. Disponível em: <http://www.capes.gov.br/capes/portal/conteudo/10/ProgramasReconhecidos.htm>. Acesso em: 14 de julho.

GATTI, Bernardete A., (1999). Mestrados e doutorados: questões de avaliação e políticas de ação. In: GATTI, Bernardete A., FÁVERO, Osmar, ANDRÉ, Marli, CANDAU, Vera Maria F. A avaliação da pós-graduação em debate. São Paulo: ANPEd, p. 29-47.

GATTI, Bernardete A., FÁVERO, Osmar, ANDRÉ, Marli, CANDAU, Vera Maria F. (1999). O modelo de avaliação da CAPES em discussão: documento básico. In: GATTI, Bernardete A., FÁVERO, Osmar, ANDRÉ, Marli, CANDAU, Vera Maria F. A avaliação da pós-graduação em debate. São Paulo: ANPEd, p. 49-63.

MADEIRA, Vicente de Paulo Carvalho, (relator) (1996). Decifra-me ou devoro-te: o enigma de uma avaliação da CAPES. Natal: Universidade Federal do Rio Grande do Norte, Programa de Pós-Graduação em Educação.

(1999). Desafios da avaliação da pós-graduação. Texto apresentado em painel, no $14^{\circ}$ Encontro de Pesquisa em Educação do Norte e Nordeste. Salvador, setembro.

Recebido em junho 2005 Aprovado em agosto 2005 


\section{Resumos/Abstracts}

Betania Leite Ramalho

Vicente de Paulo Carvalho Madeira

A pós-graduação em educação no Norte e Nordeste: desafios, avanços e perspectivas

Historia a implantação dos cursos de mestrado e doutorado em educação nas regiões Norte e no Nordeste, a partir nos anos de 1970, assim como sua consolidação em programas de pós-graduação, nos anos de 1980 e de 1990, acompanhando os Planos Nacionais de Pós-Graduação. Marca o compromisso fundamental desses programas com o desenvolvimento regional, e em especial o desenvolvimento educacional. Privilegia a análise do desafio posto pela avaliação da Coordenação de Aperfeiçoamento de Pessoal de Ensino Superior (CAPES), a partir de 1996, no desenvolvimento e na afirmação dos referidos programas. Conclui explicitando os recursos necessários para o avanço e a efetiva institucionalização da pós-graduação em educação nas regiões Norte e Nordeste.

Palavras-chave: pós-graduação em educação; regiões Norte e Nordeste; avaliação

Postgraduate studies in education in the North and Northeast regions: challenges, advances and perspectives

This article relates the process of implantation of master's and doctoral courses in education in the North and Northeast regions of the country, starting in the 70's, as well as their consolidation in postgraduate programmes in the 80's and 90's, in consonance with the National Postgraduate Plans. It affirms the fundamental commitment of these programmes to regional development and, in particular, to educational development and highlights analysis of the challenge posed by the process of evaluation instituted by CAPES, from 1996, for the development and affirmation of the same. It concludes by making explicit the resources necessary for the advance and effective institutionalization of postgraduate studies in education in the North and Northeast regions.

Key-words: postgraduate studies in education; North and Northeast regions; evaluation 